\section{Guidance for Choosing When to Use Electron and/or Light Microscopy and Related ASTM E4 Standards}

\author{
R. C. Nester \\ International Steel Group, ISG Research \\ rnester@intlsteel.com
}

Technical publications sometimes include scanning electron images to characterize a microstructure, when the relevant structure could have very easily been illustrated using a simple light micrograph. When should one use a light generated image? What are the advantages/disadvantages of an electron generated image, particularly; one generated using a scanning electron microscope (SEM)? While there is some overlap in the capabilities of these imaging systems; in general, they are complementary tools, each with their own uses. Standards under the jurisdiction of ASTM Committee E4 on Metallography offer guidance to both new and experienced users of both investigative techniques.

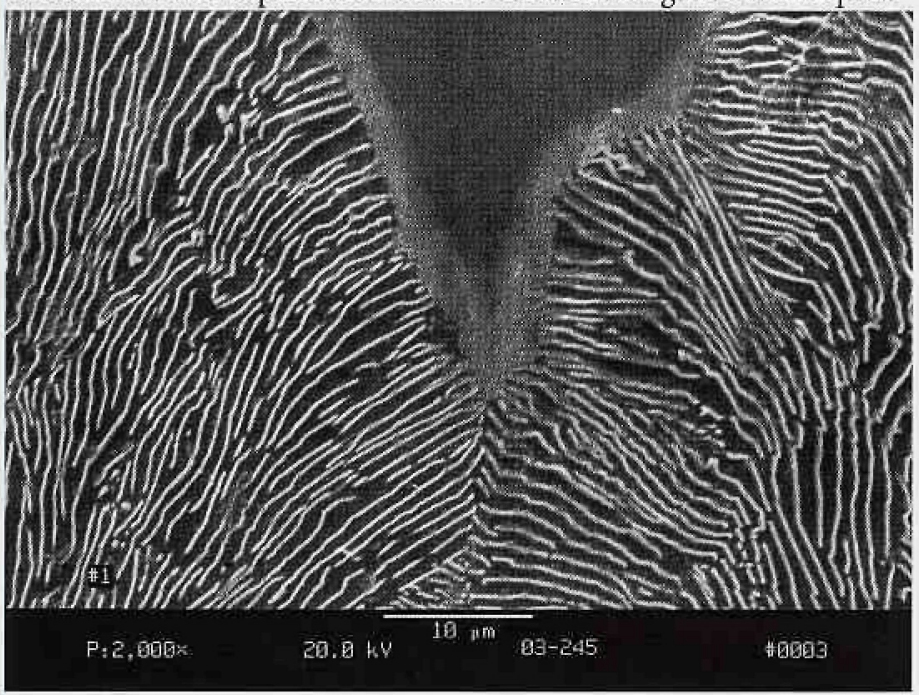

Figure 1. Secondary electron image showing the interlamellar spacing in the pearlite phase of steel. (4\% picral)

ASTM Committee E4 on metallography, which was created in 1916 in response to developments in the railroad and steel industry, has the charge of ensuring that metallographic testing standards are kept current and of use to industry and academia. E4 has evolved into a Committee of approximately 140 members having jurisdiction over 35 standards covering sample preparation, etching, and quantitative methods for both light and electron microscopy. Table 1 lists the standards, under the jurisdiction of Committee E4, which apply to electron and light microscopy [1].

Some advantages of each imaging system can be found in Table 2. When approaching a new investigation, whether it is a failure analysis or material characterization, the investigator should employ the tools that will most efficiently achieve the goals of the project.

The most obvious and significant characteristic separating the two procedures is that of resolution. Based on the theories advanced by Rayleigh and Abbe, the resolvable separation between two objects in an image is known to be proportional to the wavelength of the image source. The resolution of a SEM is dependent $3 \%$ bromine etch.

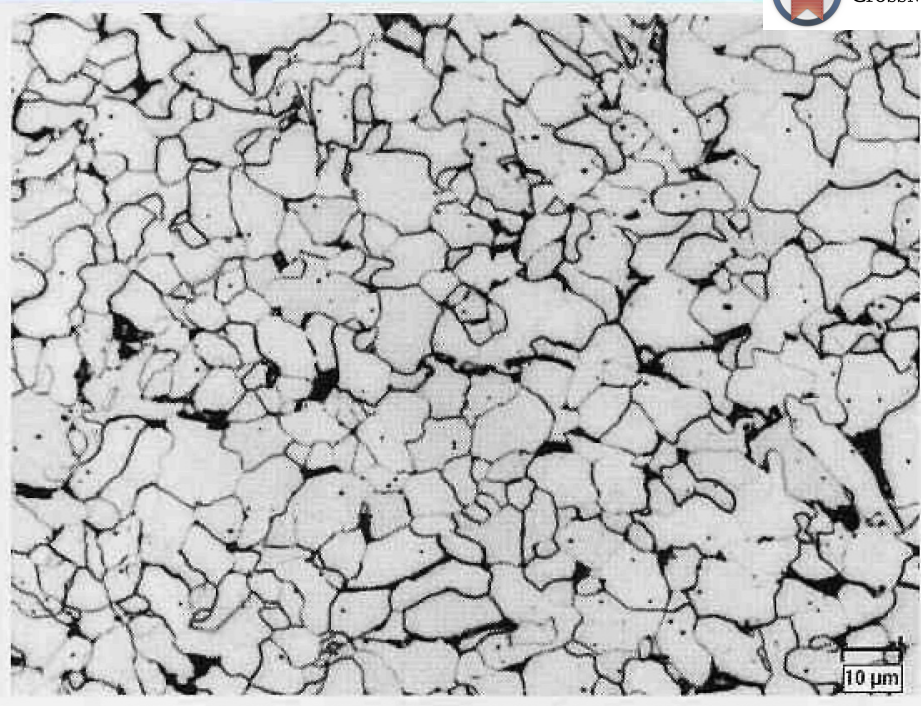

Figure 2. Light micrograph of showing ferrite and pearlite phases in steel. $(2 \%$ nital)

on many factors, including the size of the electron beam. The size of this beam can be quantified using the procedures listed in ASTM E986, "Standard Practice for Scanning Electron Microscope Beam Size Characterization", ultimately characterizing the resolution of the SEM.

In light microscopy, light waves are controlled using glass lenses and mirrors. In electron microscopy, the electrons are manipulated by electromagnetic lenses which use magnetic fields to bend and focus the electron beam much the same way that mirrors and lenses control light in an optical microscope. The harnessing of an electron beam, with its shorter wavelength, has made huge improvements in resolution allowing the illumination of matter on the atomic level [2]. Figure 1 illustrates an example of the available resolution of a secondary electron image. The interlamellar spacing in the pearlite structure is clearly evident.

While the resolution of an electron microscope may be superior to that of a light microscope, the resolution available in a light system is still very adequate for many applications. When determining the volume percent pearlite or the ferrite grain size in a steel sample, Figure 2 , there is no need to employ electron microscopy. The volume percentage of pearlite and ferrite grain size can be determined more easily and quickly with a light microscope. ASTM E562, "Standard Test Method for Determining Volume Fraction by Systematic Manual Point Count", describes a procedure for estimating the volume fraction of a constituent in a specimen by means of a point count. ASTM E112, "Standard Test Methods for Determining Average Grain Size", describes several methods for determining average grain size. While the procedure described in $\mathrm{E} 562$ can be employed for electron images, many times it easier and less time consuming too simply use light microscopy.

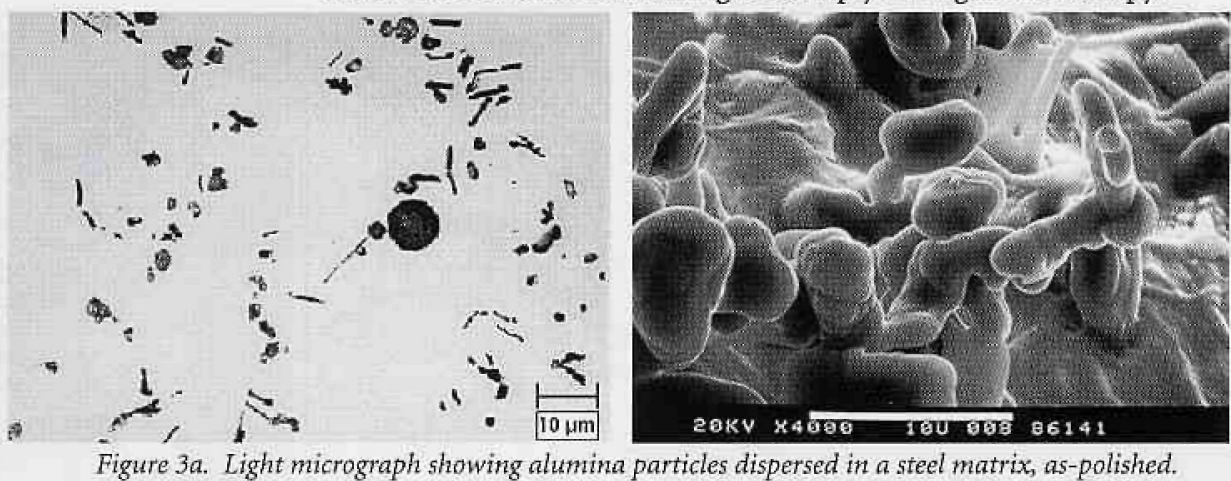

Figure 3a. Light micrograph showing alumina particles dispersed in a steel matrix, as-polished. Figure $3 b$. Secondary electron image showing three-dimensional network of alumina particles, 


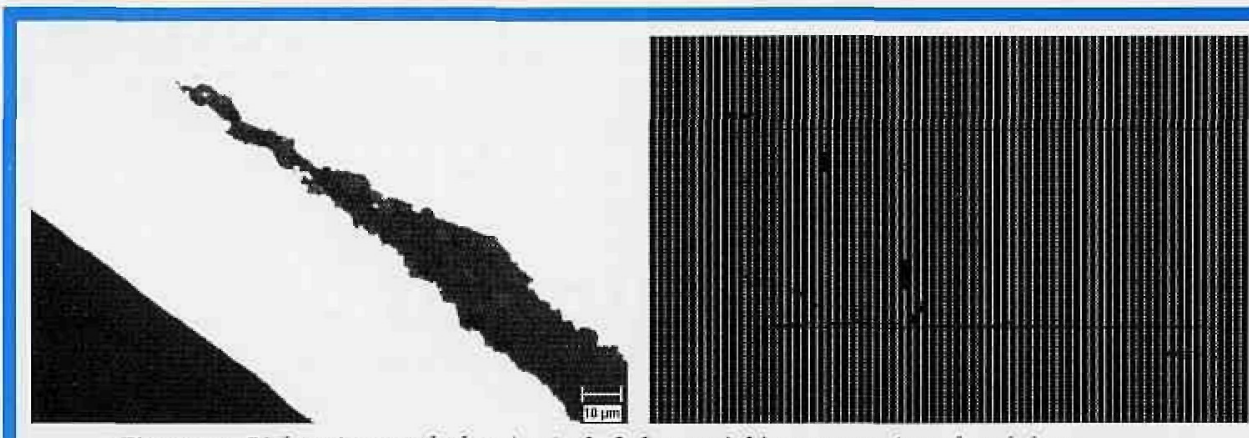

Figure 4a. Light micrograph showing included material in cross-section of steel sheet

Figure 4b. EDS spectrum of included material found in steel cross-section.

Many investigations will, ultimately, use both electron and light microscopy techniques in pursuing the goals of a particular study. Figure 3a shows an as-polished microstructure of alumina particles in material removed from the nozzle of a tundish. To evaluate size and distribution of the alumina particles in the matrix, the procedures listed in E1245, "Standard Practice for Determining the Inclusion or SecondPhase Constituent Content of Metals by Automatic Image Analysis", can be used without any need to examine the specimen using electron microscopy. However, to determine the three-dimensional morphology of the alumina, Figure $3 \mathrm{~b}$, the specimen can be examined using secondary electron imaging. Due to the virtually unlimited numerical aperture of an electron microscope, the depth of field is improved dramatically. To prepare the specimen for observation in the SEM, it was immersed in $3 \%$ bromine for several minutes to dissolve the steel matrix, leaving the alumina clusters exposed. The superior depth of field available by using a SEM, allows for the entire height of the alumina cluster to be in focus simultaneously.

Figure 4a shows a light micrograph of exogenous material en trapped in the steel substrate. With experience one could begin to

Table 1. Pertinent ASTM standards

\begin{tabular}{|l|l|}
\hline \multicolumn{1}{|c|}{ Electron Microscopy } & \multicolumn{1}{c|}{ Light Microscopy } \\
\hline E1351 - Field Replicas & E3/E768/E1920/E2015 - Specimen Prep. \\
\hline E766 - Calibrating SEM Mag & E407/E340/E381 - Specimen Etching \\
\hline E986 - SEM Performance Charact. & E112/E1181/E1245/E930/E1382 - Grain Size \\
\hline E1508 - EDS Quantitative Analysis & E45/E1122/E1245 - Evaluation of Inclusions \\
\hline E2142 - Inclusion Ratings via SEM & E562/E2109 - Volume Fraction Determin. \\
\hline & E1077/E1268 - Banding \& Decarburization \\
\hline & E1951 - Microscope Calibration \\
\hline
\end{tabular}

Table 2. Advantages of Imaging Sources

\begin{tabular}{|l|l|}
\hline \multicolumn{1}{|c|}{ Electron Microscopy } & \multicolumn{1}{|c|}{ Light Microscopy } \\
\hline Resolution & Resolution \\
\hline $\begin{array}{l}\text { Depth of field-3D appearance of } \\
\text { images- exanination of as-received } \\
\text { material }\end{array}$ & $\begin{array}{l}\text { Relatively easy nicrostructural character- } \\
\text { ization }\end{array}$ \\
\hline $\begin{array}{l}\text { Acquisition of chemical infor- } \\
\text { mation }\end{array}$ & $\begin{array}{l}\text { Relatively larger area of sampling-facilitates } \\
\text { quantitative measurements }\end{array}$ \\
\hline $\begin{array}{l}\text { Crystallographic structure/ } \\
\text { orientation information }\end{array}$ & Minimal cost of equipment \\
\hline Different illumination techniques & Different illumination techniques \\
\hline
\end{tabular}

predict what the composition of the included material may be, but to be certain, the specimen can be evaluated using energy dispersive spectroscopy (EDS). Figure $4 \mathrm{~b}$ shows the corresponding $\mathrm{EDS}$ spectrum detailing the elements present in the included material. ASTM E1508, "Standard Guide for Quantitative Analysis by Energy-dispersive Spectroscopy" offers guidance on developing EDS spectrum and information on their capabilties and limitations.

To summarize, each illumination technique has their advantages. The object of any investigation is to use both systems in a complementary fashion. If enhanced resolution, improved depth of field and information on the chemistry of a material are required in an investigation, then electron microscopy should be the tool of choice. If not, then many times a simple light microscope will be all that is required to complete the task at hand. In any case, standards under the jurisdiction of ASTM Committee E4 on Metallography (www. ASTM.org) offer information and procedures to help both the expert and novice microscopist.

The author would like to acknowledge Linford L. Hahn for his SEM images and expertise, and Richard L. Bodnar for his guidance and technical support for this presentation.

\section{References}

[1] Annual Book of ASTM Standards, American Society for Testing and Materials International, Volume 03.01, W. Conshohocken, PA, 2002.

[2] I. M. Watt, The Principles and Practice of Electron Microscopy, Cambridge University Press, Cambridge, 1985.

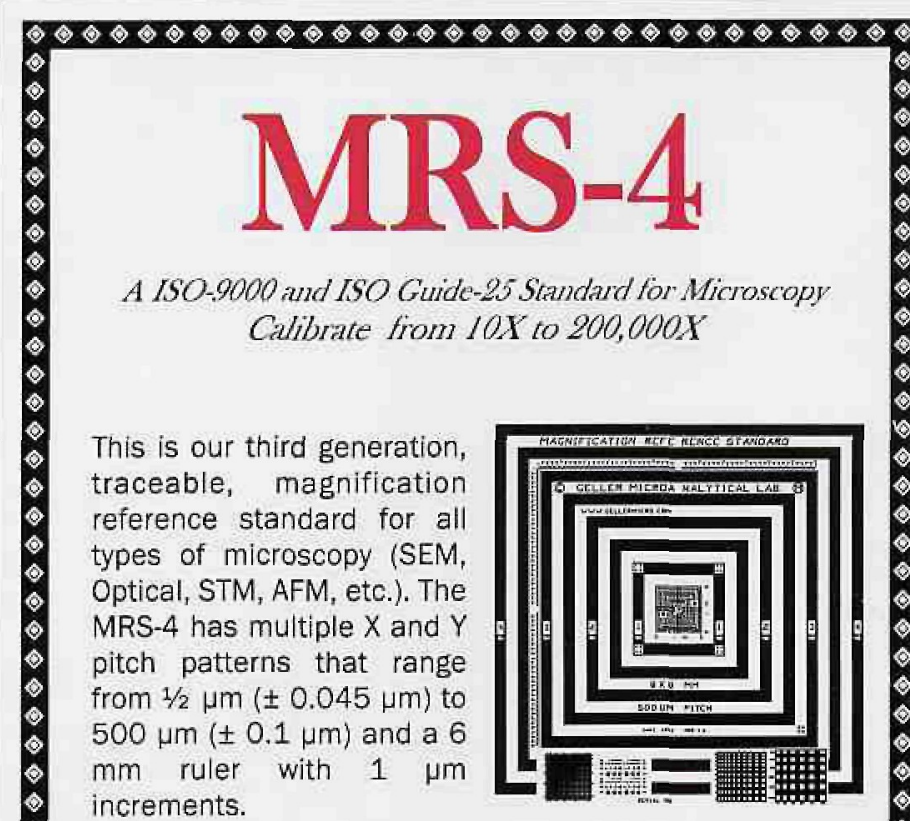

Visit our website and send for our free resources guide.

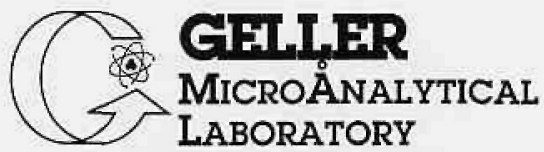

426e BOSTON STREET (RT. 1) * TOPSFIED, MA 01983

978/887-7000*978/887-6671 * je@gellermicro.com http://www.gellermicro,com

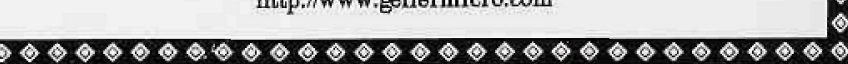

